\title{
Semi-Automatic Image Segmentation on X-Ray Image of Spine using Active Contour Method
}

\author{
Tri Arief Sardjono \\ Department of Biomedical Engineering \\ Institut Teknologi Sepuluh Nopember \\ Surabaya, Indonesia \\ sardjono@bme.its.ac.id
}

\author{
Ahmad Fauzi Habiba Chozin \\ Department of Biomedical Engineering \\ Institut Teknologi Sepuluh Nopember \\ Surabaya, Indonesia
}

\author{
Muhammad Nuh \\ Department of Biomedical Engineering \\ Institut Teknologi Sepuluh Nopember \\ Surabaya, Indonesia \\ nuh@bme.its.ac.id
}

\begin{abstract}
Currently, many image analysis methods have been developed on X-Ray of scoliotic patients. However, segmentation of spinal curvature is still a challenge, and needs to be improved. In this research, we proposed a semi-automatic spinal image segmentation of scoliotic patients from X-Ray images. This method is divided into 2 steps: preprocessing and segmentation process. A conversion process from RGB to grayscale and CLAHE (Contrast Limited Adequate Histogram Equalization) method was used in image preprocessing. The active contour method was used for the segmentation process. The result shows that segmentation of spinal $X$-ray images of scoliotic patients using active contour method interactively, can give better results. The average of ME and RAE values are $12.98 \%$ and $26.75 \%$. instead of using the interactive region splitting method which gets $21.17 \%$ and $89.27 \%$.
\end{abstract}

Keywords: active contour, interactive segmentation, preprocessing, scoliosis.

\section{INTRODUCTION}

Scoliosis is a spinal deformity that represents lateral deviation of the vertebrae and followed by rotational vertebrae. This lateral curvature of the spine is also associated with a change in the curves in sagittal plane and vertebral rotation [1]. Detecting scoliosis as early as possible is needed especially in screening programs, and special care and further evaluation should be done when patients are indicated with positive scoliosis screening results. This goal is to identify patients who are at risk of developing problems from scoliosis [2]. A special Curvature of the spinal column can be caused by several factors, such as idiopathic, food-borne infections or improper posture [3].

Currently, diagnostic technology for X-ray images has evolved film-based and/or using fully digital format or commonly known as digital medical imaging. X-ray images of the spinal column can give useful information by understanding and extracting its features. However, the disadvantages of these X-rays are the appearance of noise, low contrast, and radiation exposure [4]. This problem makes the interpretation relatively difficult and can cause errors in the diagnosis.

The active contour is the type of deformable model for segmentation. Active contour can move to the region of interest and is able to segment the area [5]. Image segmentation is the process of dividing an image into homogeneous areas based on a certain criterion between the gray level of a pixel and the gray level of its neighboring pixels.

We proposed a semi-automatic segmentation method to segment the spine X-Ray image of a scoliotic patient using active contour. In general, this process involves 2 stages, first, the preprocessing process, a converting RGB images to grayscale images and enhancing image contrast using CLAHE method. In the second stage, active contour was used to segment the image to get the desired image pattern with manual initial contour position.

\section{A. Images Pre-processing}

The pre-processing stage aims to improve the quality of an image. Images generated from data acquisition equipment such as X-rays are often unable to produce a desired quality image. Noise and low contrast make it difficult to distinguish between the object and noise in the image. A pre-processing stage, conversion of RGB images to grayscale and quality enhancement (contrast, brightness, CLAHE) are needed to give a better result.

Point processing and mask processing could be used in image enhancement. Point processing is an operation that is performed on each pixel, while mask processing is an operation that is performed on a neighboring window in the image. The convolution will be carried out on a mask for a particular window. The purpose of convolution is to obtain a pixel based on the pixel value itself and its neighbors.

1) (Contrast Limited Adequate Histogram Equalization)

A histogram equalization process is needed to find a mapping of the grey level of each image pixel. This stretched the grey level value with a new distributed gray level value. One of the popular methods of histogram equalization is the proposed Contrast Limited Adaptive Histogram Equalization (CLAHE) [6]. CLAHE were applied on many applications such as for linear spectral clustering [7], Ostearthritis classification [8], real-time image enhancement [9] with all its variations [10].

\section{B. Images Segmentation}

Segmentation is the process of separating one object from another object in an image into objects based on certain characteristics. The segmentation process stops when the desired object has been found. The purpose of segmentation is to find the special characteristics of an image. Images are simplified or represented in a picture that is easier to analyze. Therefore, segmentation is needed in the pattern recognition process. The better the quality of the segmentation, the better the quality of pattern recognition.

\section{Active Contour}

The concept of Snakes models or active contour models was first introduced in 1987 and later developed by various researchers [11]. Active contour uses the principle of energy minimizing which detects certain features in the image. It is a flexible curve (surface) that can dynamically adapt to the desired edge or object in the image. This system consists of a 
set of points that are interconnected and controlled by a straight line, as shown in Fig. 1.

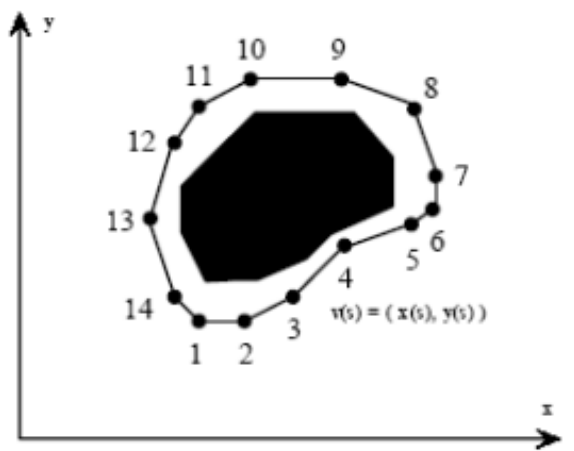

Fig. 1. Basic Form of Active Contour

Active contour models will create an initial contour that surrounds the object, then the grey level value of an image object will cause the curve to shrink and follow its pattern. Active contour is described as several controlled points that move sequentially. Determining the object in the image through active contour is an interactive process. The user usually puts an initial position contour, as shown in Fig. 1, which is close to the object's shape. Furthermore, the contour will be attracted towards the features in the image due to the influence of the internal energy that produces the image. This movement is influenced by the iteration value so that the segmentation process runs and detects the edges of the desired object.

The energy function described as active contour consists of internal energy and external energy. The internal energy makes the curve compact (elastic force) and its boundaries make very sharp turns (bending force). External forces tend to make curves move toward the object boundaries.

Internal energy, the sum of elastic energy and flexibility energy, can be expressed in Eq. 1.

$$
\begin{gathered}
E_{\text {int }}=E_{\text {Elastic }}+E_{\text {bend }}=a(s)\left|\frac{d v}{d s}\right|^{2}+ \\
\beta(s)\left|\frac{d^{2} v}{d s}\right|^{2}
\end{gathered}
$$

Where $a$ is the constant of the elasticity variable and $\beta$ is the constant of the curvature of the contour curve. The energy elasticity and flexibility can be defined in Equation 2 in Equation 3.

$$
\begin{aligned}
& E_{\text {Elastic }}=\int_{s} a(v(s)-v(s-1))^{2} \cdot d s \\
& E_{\text {bend }}=\int_{s} \beta(v(s-1)-v(s)+v(s+1))^{2} \cdot d s
\end{aligned}
$$

The energy minimization function can be shown in Eq. 4.

$$
\begin{aligned}
E_{\text {sanke }}^{*} & =\int_{0}^{1} E_{\text {snake }}(v(s)) \cdot d s \\
& =\int_{0}^{1}\left\{E_{\text {int }}(v(s))+E_{\text {con }}(v(s))\right\} \cdot d s
\end{aligned}
$$

Where $E_{\text {int }}$ is the internal energy of the curve, and $E_{\text {con }}$ is the external energy.

Active contour method was applied in many research areas especially in the medical image analysis field [12-16].

\section{METHODS}

Fig. 2 shows the block diagram of the proposed method, which consists of 2 parts, image preprocessing and image segmentation. The first step, we convert RGB images to grayscale images. The contrast enhancement method which is carried out using the CLAHE method to increase the image contrast. The next step is the semi automatic segmentation process. This process involved manual user interaction to initialize the edge of the desired object. The segmentation spinal curvature can be 'S' or 'C' shaped. The main objective of this process is to separate the object of spinal curvature from the background so that the initialization process of the curvature of the spine will not be disturbed by other cluttered objects.

\section{A. Image Preprocessing}

Image improvement and enhancement were applied on107 Spinal X-ray images of scoliotic patients, with 'C' and 'S'. We need to select the spinal images with both image quality and intensity. CLAHE (Contrast Limited Adequate Histogram Equalization) was used to improve image contrast. CLAHE operates on a small area in the image so that the resulting

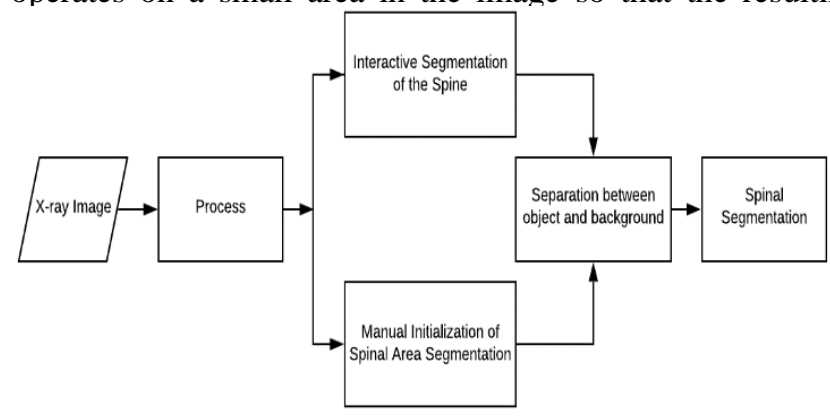

Fig. 2. Block Diagram of Proposed metod

histogram is uniform with the desired histogram shape. This method is formulated based on dividing the intensity of the image into several areas.

\section{B. Image Segmentation}

The object of focus in this research is spinal abnormalities in " $\mathrm{C}$ " and " $\mathrm{S}$ " shape. To simplify the segmentation process, we separate the object and background in such a way (background removal). The background removal process is carried out by means of an interactive segmentation method. The interactive segmentation method will involve the user in separating the object and background regions by initializing the object edge to indicate the object boundary. The advantage of interactive image segmentation is that low contrast images can be segmented more accurately. In addition, other required information such as grayscale intensity or texture provided will help the segmentation process. The interactive segmentation process begins with creating an initial curve; a small circle placed on the edge of the desired spinal curvature manually. The next process is to give the iteration value and start the segmentation process

\section{Testing and Evaluation}

Testing and evaluation is necessary to find out how optimal our proposed methods are. Misclassification Error (ME) and the Relative Foreground Area Error (RAE) were used to evaluate the effectiveness of this method. 


\section{RESULTS AND DISCUSSIONS}

\section{A. Image Pre-processing}

The process of semi-automatic Spinal segmentation using active contour is shown in Fig. 3. The contrast level was carried out by providing a certain limit value, and intensity above this value will be over limit. The intensity value that exceeds will be distributed to the area below the limit value, so the intensity distribution value will be evenly distributed.

Fig. 3 (a) and (b) show the original image and its histogram. Fig. 3 (c) and (d) are the image results after the CLAHE process and its intensity distribution histogram.

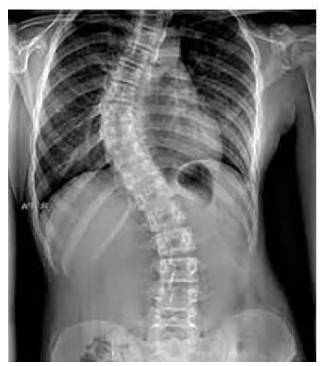

(a)

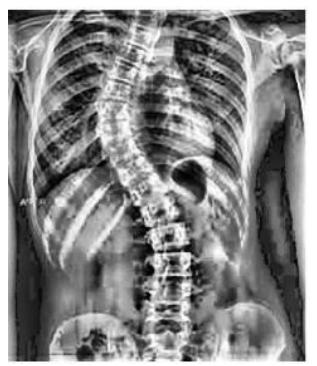

(c)

2000 Iterations

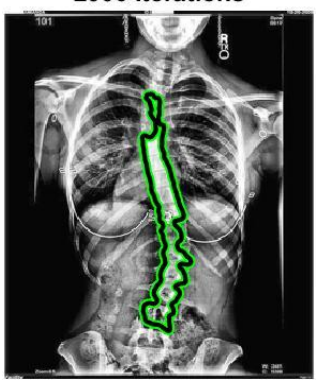

(e)

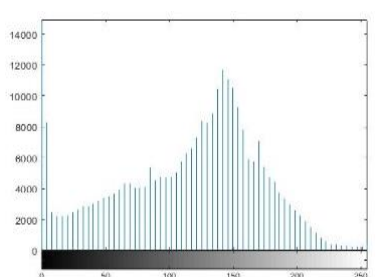

(b)

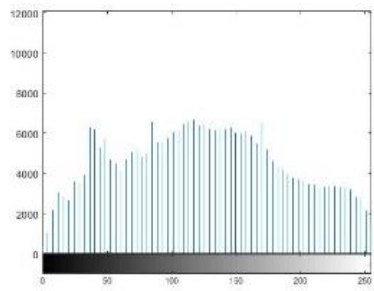

(d)
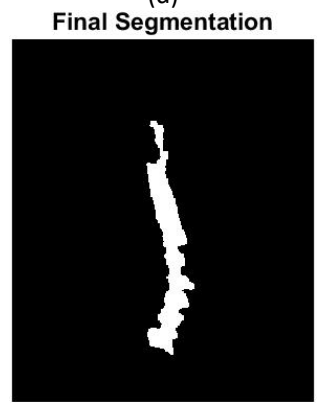

(f)
Fig. 3. The process of semi-automatic Spinal segmentation using active contour. (a) Original image, (b) original image histogram, (c) CLAHE result image, (d) CLAHE image histogram, (e) Active contour segmentation process, (f) segmentation results

\section{B. Image Segmentation}

We have evaluated the processing time and the results of the segmentation. The average processing time is 1 minute 50 seconds by using prosesor Radeon Vega Mobile Gfx, 8 GB RAM DDR4, GPU AMD Ryzen R5 2GB and 16 seconds by using Intel(R) Core (TM) i7-8700, 16 GB DDR4, GPU Nvidia GeForce GTX1650 4GB. The processing time really depends on the hardware specifications. The interactive contour segmentation has better segmentation results with small error. The active contour segmentation result is strongly influenced by the distribution of grayscale intensity in the image. For this reason, at the stage of giving the initialization, we must pay more attention to the distance from the ROI and the intensity of its neighboring area. The contour will move from the initial point and will stop when the contour finds a homogeneous value as shown in Fig. 3 part (f). The movement of the contours is strongly influenced by differences in pixel intensity values, and this affects the iteration process and segmentation results. Even though the number of input iterations has not been completed, the movement of the contour curve will stop when it has found a homogeneous value, but the iteration will continue until the number of iterations is determined. When the iteration process stops, the object in ROI will be converted into binary form as shown in Fig. 3 part (f).

An interactive region splitting was used to reduce processing time. This interactive segmentation process for region splitting begins with region mapping that is homogeneous or has a similar greyscale value. The marking was put on the image interactivity by using a mouse.

We have compared our method with the region splitting segmentation method. The ME and RAE of interactive region splitting segmentation method is $21.17 \%$ and $89.27 \%$. By using our method, the average error value is $12.98 \%$ for ME and 26.75 for RAE. The active contour method gives smaller errors but is time consuming. To speed up the iteration time, we have used a lower resolution image.

\section{CONCLUSIONS}

We have done the semi-automatic spinal segmentation using Active Contour method. The processing time duration and the segmentation results were evaluated. The processing time depends on the hardware specifications. In the segmentation process using the active contour method interactively give better results with $\mathrm{ME}$ and RAE $12.98 \%$ and $26.75 \%$ respectively. By using interactive region splitting methods, the values of ME and RAE are $21.75 \%$ and $89.27 \%$. These results show that the segmentation using active contour method is more effective.

\section{REFERENCES}

[1] S. Mukaromah, Pengalaman Psikososial Remaja Penyandang Skoliosis di Wilayah Karesidenan Surakarta, Depok: Tesis, progam Magister Ilmu Keperawatan Universitas Indonesia, 2011.

[2] L.Hansen, M. De Zee, J. Rasmussen, T. B. Andersen, C. Wong, and E. B. Simonsen, "Anatomy and Biomechanics of the Back Muscles in the Lumber Spine with Reference to Biomechanical Modelling," Lippincot Williams \& Wilkins, vol. 31, no. 17, pp. 1888-1899, 2006.

[3] Mujahiddin, A. A. Susijanto, T. R. Madha, C. W. dan W. Sandhy, "Segmentasi Citra Tulang Belakang Menggunakan Charged Particle Model," Joones, vol. 3, no. 1, pp. 24-32, 2014.

[4] Teresa, Pewarnaan Citra Grayscale ke dalam Citra Berwarna dengan Menggunakan Pseudocoloring berbasis Palet Warna, Jenis Laporan, Institut Teknologi Bandung: Bandung.

[5] Gonzales R.C and Woods R.E, Digital Image Processing Second Edition, New Jersey: Pearson Prentice Hall, 2004.

[6] V. Casellas, R. Kimmel, and G. Sapiro, "Geodesic Active Contour," Internasional Journal of Computer Vision, vol. 22, no. 1, pp. 61-79, 1997.

[7] A. M. Reza, "Realization of the Contrast Limited Adaptive Histogram Equalization (CLAHE) for Real-Time Image Enhancement," J.VLSI Signal Process, vol. 1, no. 38, pp. 35-44, 2004.

[8] D. Cremers, F. Tischhauser, J. WEicket, and C. Schnorr, "Diffusion Snakes: Introducing Statistical Shape Knowledge into the MumfordShah Functional," Int. Journal of Computer Vision, vol. 3, no. 50, pp. 295-313, 2002.

[9] Y. N. Nabusa, "Pengolahan CItra Digital Perbandingan Histogram Equalization dan Specification pada Citra Abu-Abu," Jurnal Komputer dan Informatika, vol. 7, no. 1, pp. 87-95, 2019. 
[10] A. Rizal, Analisis Contrast Limited Adaptive Histogram Equalization (CLAHE) dan Region Growing dalam Deteksi Gejala Kanker Payudara pada Citra Mamogram, Bandung: Tugas Akhir, Telkom University, 2014.

[11] S. M. Pizar, E. Philips Amburn, J. D. Austin, R. Cromatie, A. Gezelowith and T. Greer, "Adaptive Histogram Equalization and Its Variations," Computer Vision, Graphics and Image Processing, vol. 39, no. 3, pp. 355-368, 1987.

[12] S. M. Pizar, E. Philips Amburn, J. D. Austin, R. Cromatie, A. Gezelowith and T. Greer, "Adaptive Histogram Equalization and Its Variations," Computer Vision, Graphics and Image Processing, vol. 39, no. 3, pp. 355-368, 1987.

[13] Nurpadmi, Segmentasi Tulang pada Citra CT Menggunakan Active Contour, Surabaya: EEPIS Repository, 2010.

[14] N. Aini, C. Fatichah, dan B. Amaliah, "Pemisahan Sel Bertumpuk Citra Sel Kanker Payudara Menggunakan Metode Region-Based Active Contour dan Bayesian," SCAN, vol. 10, no. 3, pp. 17-24, 2015.

[15] D. U. Dewangga, Adiwijaya dan D. Q. uatama, "Identifikasi Citra berdasarkan Gigitan Ular menggunakan Metode Active Contour Model dan Sopport Vector Machine," Jurnal Media Informatika Budidarma, vol. 3, no. 4, pp. 299-306, 2019.

[16] Suprijanto, F. I. Muchtadi, dan I. Setiawan, "Segmentasi Citra Secara Semi Otomatis Untuk Visualisasi Volumetrik Citra CT-SCAN Pelvis," Makara Teknologi, vol. 13, no. 2, pp. 58-66, 2009.

[17] F. Basyid, dan K. Adi, "Segmentasi Citra Medis Untuk Pengenalan Objek Kanker Menggunakan Metode Active Contour," Youngster Physics journal, vol. 3, no. 3, pp. 209-216, 2014.

[18] E. Permata, "Penggunaan Metode Active Contour Untuk Segmentasi Parasit Malaria Plasmodium Falciparum," SIMETRIS, vol. 6, no. 1, pp. 163-174, 2015

[19] Zulkarnain dan S. Syaputri, "Segmentasi Citra Thorax Paru-Paru Manusia Dari Sinar X Menggunakan Metode Active Contour," Jop, vol. 4, no. 2, pp. 8-10, 2019. 